\title{
Estudo da Qualidade Microbiológica e Físico-Química de Leites Uht Comercializados no Município de Dois Vizinhos - PR
}

\author{
Marcela Tostes Frata (I), Alex Júnior Bachi (I), Jhone Gleison de \\ Oliveira (I), Ângela Elis Schneider (I)
}

(I) UTFPR - Universidade Tecnológica Federal do Paraná (Estrada para Boa Esperança, Km 04 CEP 85660-000 - Dois Vizinhos - PR )

\section{Resumo}

A produção de leite UHT (ultra high temperature) no Brasil apresentou grande evolução ao longo de 20 anos, passando de 450 milhões de litros para mais de 6 bilhões de litros em 2012. Recentes notícias divulgadas pela imprensa apontam a ocorrência de adulterações em leites UHT no país. O objetivo deste trabalho foi analisar as características físico-químicas e microbiológicas de dez marcas de leite UHT integral, comercializadas no município de Dois Vizinhos, PR, a fim de verificar se estavam seguros, sem fraudes e alteração das características físico-químicas e nutricionais. Utilizaram-se duas embalagens de cada marca, do mesmo lote, em duplicata. Para a contagem total de aeróbios mesófilos as embalagens foram incubadas em estufa a $37^{\circ} \mathrm{C}$, por 7 dias e analisadas de acordo com os métodos propostos pela legislação. As análises de $\mathrm{pH}$, sólidos não gordurosos (SNG), teor de gordura, proteína, densidade, crioscopia e teor de água adicionada foram realizadas em analisador de leite (Lactoscan SLP), já a acidez titulável e a adição de peróxido seguiram metodologia descrita pela legislação e foram executadas nos laboratórios da Universidade Tecnológica Federal do Paraná, Câmpus Dois Vizinhos. Os resultados foram comparados com a legislação brasileira e do Mercosul. Todas as amostras apresentaram-se dentro do limite máximo de 100 $\mathrm{UFC} / \mathrm{mL}$ de aeróbios mesófilos, sendo que a contagem mais elevada foi de $48 \mathrm{UFC} / \mathrm{mL}$, portanto, todas estavam seguras do ponto de vista

\footnotetext{
Referência:

Marcela Tostes Frata, Alex Júnior Bachi, Jhone Gleison de Oliveira, Ângela Elis Schneider.Estudo da Qualidade Microbiológica e Físico-Química de Leites Uht Comercializados no Município de Dois Vizinhos - Pr. In: Anais do 12을 Congresso Latinoamericano de Microbiologia e Higiene de Alimentos - MICROAL 2014 [= Blucher Food Science Proceedings, num.1, vol.1]. São Paulo: Editora Blucher, 2014. 
microbiológico. Seis amostras apresentaram $\mathrm{pH}$ acima de 6,8, podendo ser indicativo de fraude por adição de substâncias alcalinas ou falha na lavagem dos equipamentos. Somente uma amostra apresentou acidez titulável acima de $18^{\circ} \mathrm{D}$, possivelmente decorrente da elevada contaminação microbiana no leite cru. Oito amostras apresentaram SNG abaixo do preconizado de $8,2 \%$, provavelmente, em função do tipo de alimentação fornecida aos animais. O teor de gordura de todas as amostras estava adequado. Somente duas amostras apresentaram teor de proteínas abaixo do recomendado de $2,9 \%$, valor de densidade abaixo de $1,027 \mathrm{~g} / \mathrm{mL}$ e crioscopia fora dos parâmetros e, ainda, acusaram a presença de fraude por adição de água. Nenhuma amostra apresentou fraude por adição de peróxido de hidrogênio. Dessa forma, pôde-se constatar que somente uma amostra de leite UHT, dentre as dez testadas, estava de acordo com os parâmetros de qualidade.

Palavras-Chave: avaliação microbiológica, fraude em leite, qualidade de lácteos

Agência de Fomento: 